\title{
Comparison of NCHS-1977, CDC-2000 and WHO-2006 Nutritional Classification in 32 to 60 month-old Children in the Central Highlands of Peru (1992-2007)
}

\author{
Doris Maritza Chirinos Peinado*, Jorge Isaac Castro Bedriñana \\ Maestría en Seguridad Alimentaria Nutricional, Universidad Nacional del Centro del Perú, Huancayo. Perú \\ *Corresponding Author: chirinosdoris@yahoo.com
}

Copyright (C) 2013 Horizon Research Publishing All rights reserved

\begin{abstract}
Objective. The aim is to compare the three references used for the classification of the nutritional status of 36 to 60 month-old children in Huancayo province (Peru). For a long time, NCHS-1977 reference has been used for child growth monitoring, recently the new WHO-2006 Child Growth Standards is being used, and CDC-2000 reference usage has been restricted. Methods. Data collected from 2640 children over the period 1992 to 2007 served as basis for determining the nutritional children status using Anthro V.3.0 and EpiInfo 6.04. Internationally cutoff points used in every assessed reference system helped to determine the nutritional status and to calculate the Z-scores of height-for-age, weight-for-age, weight-for-height and body mass index differentiated by sex. Results. The underweight, stunting and wasting percentages (period 992-2007), determined with NCHS-1977 reference were 8.4\%, 28.8\% and $0.9 \%$; with CDC-2000 reference were $10.2 \% ; 19.1 \%$ and $3.3 \%$, and with WHO-2006 standard were $6.6 \%, 33.9 \%$ and $1.4 \%$ respectively. The overweight and obesity percentages determined with CDC-2000 standard were $11.4 \%$ and $4.20 \%$, and with WHO-2006 standard were $8.0 \%$ and $0.9 \%$, respectively. Conclusions. A more realistic and accurate detection of malnutrition prevalence in 36-to-60 month-old children from Huancayo province was carried out using the new WHO Child Growth Standard. Using the CDC-2000 standard is recommended in overweight monitoring cases.
\end{abstract}

Keywords Nutritional Status, Underweight, Stunting, Wasting, Anthropometric Assessment, Child Growth Standards, Central Highlands of Peru

\section{Introduction}

\subsection{Poverty and Malnutrition in Peru}

Most people in the Andean Region live in deprivation and poverty conditions and Peru is not the exception. As for 2007,
$42.5 \%$ lived in poverty and $12 \%$ in extreme poverty, $74.0 \%$ and $58.1 \%$ of poverty corresponds to rural zone and highland region respectively [1]. In 2004, 67.3\% of preschool population was in poverty conditions [2]. Therefore, the stunting prevalence in children under five years, for 2000 and 2007 was $25.4 \%$ and $22.6 \%$, respectively [3,4]. In many Andean communities sometimes poverty reached to $100 \%$ [5], overweight related to energy-dense diets with highly regressive distribution of stunting in lower income groups was found [6], while the health and social services distribution benefit the higher income groups of urban zone [7]. Obesity was reported in children under five $(6.3 \%)$ placing Peru in the eighth position after Algeria (9.2\%), Egypt (8.6\%), Argentina (7.3\%) and Chile (7\%) [8].

The Uñas-Huancayo-Peru community study to assess the nutritional status of preschool children reported $48.9 \%$ of low weight for age and $44.4 \%$ of stunting [9]. In Junin department, the national survey of demography and health (ENDES, 2000) reported $31.3 \%$ of stunting and $10.5 \%$ of several stunting in children under five [4]. In another study in Janjaillo district (Jauja-Peru, 3698 masl.), stunting (17.8\%) and severe stunting (51\%) was reported in children under 5 [5]. With regard to wasting prevalence for the years 1975 [10], 1984 [11], 1991/92 [12], 1996 [3] and 2000 [4], the percentages were $2.2 \%, 0.4 \%, 1.4 \%, 1.1 \%$ and $0.9 \%$, respectively. In Junin department, ENDES-2000 reported $1.8 \%$ of wasting and $0.7 \%$ of severe wasting in children under five [4]. With regard to underweight for the same years, the prevalence percentages were $16.1,13.4,10.8,7.8$ and 7.1 respectively. In Junin department, ENDES-2000 reports $10 \%$ of underweight in children under five [4].

According to National Institute of Health of Peru, the obesity prevalence in children under five for 2002 and 2004 was $4.4 \%$ and $5.7 \%$, respectively [13]. Another study, which evaluated 1830 children in rural areas reported $10.4 \%$ of overweight, $2.0 \%$ of obesity and $49 \%$ of stunting, which indicates that overweight and obesity coexist with stunting [14], not being rare that in the same household malnourished or overweight children and adults live together $[7,15]$. 


\subsection{Nutritional Transition and Anthropometric Assessment Fundamentals}

Nutritional transition concept is a relevant paradigm for public health as a response to poverty in Latin America [3, 4,16], where excess and deficit problems coexist in the same community or family, reflecting a trend of high carbohydrates and low fiber diets associated with adulthood chronic diseases $[17,18]$. As nutritional deficit in early age continues, this situation will not change. So, Body Mass Index (BMI) of Quetelet $(\mathrm{kg} / \mathrm{m} 2)$ was used again to evaluate the nutritional status of adults [19] and young people [2,20]. This system, that takes over OMS [21] new proposal based on the use $\mathrm{Z}$ scores of height for age, weight for height, weight for age and IMC, can be determined easily by using EpiInfo 6.04 [22] and Anthro V.3.0 [23].

$\mathrm{Z}$ scores correspond to different standards, Center for Health Statistics of the United States (NCHS-1977) [24], Center for Disease Control and Prevention of the United States (CDC-2000) $[25,26]$ and recently the new WHO growth pattern-2006 [21]; methodologies that are being evaluated in many country populations, as in the central highlands of Peru.

The use of the new WHO-2006 pattern will allow a better estimation of the nutritional status in children under five in comparison to NCHS and CDC standards [20]. These findings were reported in a study with children from 26 human settlements in the province of Chiclayo, in the northern department of Lambayeque-Peru [2].

\subsection{Multicenter Study and New WHO Growth Pattern}

WHO, in 1993, after a thorough review of the application and interpretation of anthropometric patterns, recognized that the NCHS standard did not adequately represent growth in early childhood for having been created with a database obtained 50 years before the processing, based in children fed with formulas during the first years $[14,24]$. Therefore, they planned generate more accurate growth charts [20,27], considering breastfeeding during the first 6 months of life $[20,21,27,28]$, through the completion of a multi-site study from 1997 to 2003, with more than 8000 children from various parts of the world (Brazil, United States of America, Ghana, India, Norway, Oman), maintaining optimal health and nutritional requirements in their care; generating a new proposal on appropriate growth of children, pattern that has been validated in many countries and environmental conditions for using in diagnosis, prevention, promotion and intervention and reduce childhood nutritional problem and therefore the chronic diseases in adulthood, facilitating the evaluation of the poverty, health and development [29].

As background to this study, there is a study in 587 children aged 2-5 years in Chiclayo, Peru [2], which compared the nutritional status using the NCHS-1977 and CDC-2000 references. Using the NCHS-1977 reference, $18.9 \%$ of stunting, $4.3 \%$ of underweight and $0.2 \%$ of obesity was reported and no child had acute malnutrition. The percentage of obesity defined using IMC system was $6.3 \%$. It concluded that NCHS-1977 reference would be more rigorous to determine deficit problems as stunting, whereas overweight problems would be better defined with BMI-CDC system.

In this sense, given the limited evidence on the behavior of various anthropometric references to justify its adoption in highlands, the study objective was to determine the nutritional status evolution in children of 3 to 5 years in Huancayo province-Peru, assessed during 16 years, divided into four time periods (1992, 1993-1997, 1998-2002 and 2003-2007), with three evaluation systems as well as to verify that the new WHO growth pattern detect, in a more precise way, nutritional problems than NCHS and CDC standards.

\section{Materials and Methods}

\subsection{Place and Duration}

The study was performed in 25 of 28 districts of Huancayo province, Junin-Peru: Ahuac, Cajas, Chilca, ChongosBajo, Chupaca, Chupuro, Cochas Chico, Cullpa Baja, El Tambo, Huancayo, Hualhuas, Huancán, Huayucachi, Ingenio, Manzanares, Pilcomayo, Pucará, Quilcas, San Jerónimo, Sapallanga, Sausa, Sicaya, Tres de Diciembre, Uñas and Viques, located between 3250-3500 MASL, using a data basis that was generated for 16 years (1992-2007).

\subsection{Population and Sample}

Children of 36 to 60 month old of Huancayo province. The sample was 2640 children: 1268 men and 1372 women four chronological periods: 1) Baseline, 1992, with 532 children (20.2\%), 2) 1993-1997, with 370 children (14\%), 3) 1998-2002, with 494 children (18.7\%) and 4) 2003-2007, with 1244 children (47.1\%).

Inclusion criteria: children of 36 to 60 month old born in the districts included in the study and who continued to live there, clinically healthy children, written permission of the mother to take part in the study. Exclusion criteria: children with low birth weight or premature birth and those who were 5 years old post-dates the measurements made, children without date of birth documents or with incomplete anthropometric measures.

\subsection{Study Design}

The study considered the evaluation of Z-scores and prevalence of stunting $(\mathrm{H} / \mathrm{A})$, wasting $(\mathrm{W} / \mathrm{H})$, underweight (W/A), overweight and obesity (W/T and BMI), using NCHS-1977, CDC-2000 and WHO-2006 references.

\subsection{Anthropometric Assessment}


Anthropometric measurement techniques responded to WHO recommendations [27]. Weight was measured on digital scales Unicef-SECA with $\pm 100 \mathrm{~g}$ precision. Height was measured in standardized height boards with $+1 \mathrm{~mm}$ accuracy. To calculate the age, the birth date indicated in birth certificate or growth card was considered.

Anthropometric indices were determined on the basis of $\mathrm{Z}$-scores weight for age ( $\mathrm{Z} \mathrm{W} / \mathrm{A})$, height for age $(\mathrm{Z} \mathrm{H} / \mathrm{A})$, weight for height $(\mathrm{Z} \mathrm{W} / \mathrm{H})$ and weight/height2 ( $\mathrm{Z}$ BMI), using EpiInfo 6.04d4 [22] and Anthro V.3.0 [23]. To determine the nutritional status, we used internationally recommended cutoffs $[19,22,26,30]$ : Normal $(-1.0$ to +1.0 $\mathrm{SD})$, risk of stunting (-1.0 to $-2.0 \mathrm{SD})$, stunting ( -2.0 to -3.0 $\mathrm{SD}$ ), severe stunting (less than $-3.0 \mathrm{SD}$ ), overweight (1.0 to 2.0 SD), obesity (Z greater than $2.0 \mathrm{SD}$ ).

\subsection{Processing and Data Analysis}

The information was processed using SPSS V16.0 and Excel. To compare children nutritional status classified with three international standards, were elaborated relative frequency tables. Time trends were analyzed based on the 4 periods, drawing line charts for wasting, stunting, underweight and overweight-obesity based on BMI. For ease of writing and reading, NCHS-2007, CDC-2000, OMS-2006 references are indicated as NCHS, CDC and WHO respectively.

\subsection{Ethical Consideration}

Before anthropometric assessment, mothers were informed about the study and its objectives, the anthropometric measurements, the safety participation of their children in the study and the benefits. Mothers who agreed voluntarily to take part in the study signed the consent formulary. Mothers of children with stunting received directions to improve their nutritional and food level using resources available in the area. In addition health centers of the respective districts became aware of the problem for intervention measures.

\section{Results}

The percentage of underweight was greater with CDC reference, followed by NCHS and WHO (Table 1).

The overweight and obesity percentages were $2.1 \%, 2.3 \%$ and $1.9 \%$ with NCHS, CDC and $\mathrm{WHO}$ respectively. CDC did really well detecting overweight while overweight detection decreased from $2.30 \%$ to $1.9 \%$ with WHO.

WHO detected greater stunting prevalence. The total stunting percentages (include severe stunting) were $28.8 \%$, $19.1 \%$ and $33.9 \%$ when using NCHS, CDC and WHO. New WHO Pattern determined lower high stature percentage, which was higher with CDC and NCHS references (Table 2).
Table 1. Nutritional classification based on Z-score weight/age-Period 1992 to $2007(\mathrm{n}=2640)$.

\begin{tabular}{|c|c|c|c|}
\hline & NCHS & CDC & OMS \\
\hline $\begin{array}{c}\text { Obesity } \\
\text { (Z W/A >2), } \%\end{array}$ & 0.20 & 0.00 & 0.00 \\
\hline $\begin{array}{c}\text { Overweight } \\
\text { (Z W/A 1 to 2), \% }\end{array}$ & 1.90 & 2.30 & 1.90 \\
\hline $\begin{array}{c}\text { Normal } \\
\text { (Z W/A -1 to 1) } \%\end{array}$ & 50.70 & 55.80 & 57.90 \\
\hline $\begin{array}{c}\text { Underweight risk } \\
\text { (Z W/A -2 to -1), \% }\end{array}$ & 38.80 & 31.70 & 33.70 \\
\hline $\begin{array}{c}\text { Underweight } \\
\text { (Z W/A <-2), \% }\end{array}$ & 8.40 & 10.20 & 6.0 \\
\hline
\end{tabular}

Table 2. Nutritional classification based on Z-score height/age - Period 1992 to $2007(\mathrm{n}=2640)$.

\begin{tabular}{|c|c|c|c|}
\hline & NCHS & CDC & OMS \\
\hline $\begin{array}{c}\text { High stature } \\
(\mathrm{Z} \mathrm{T} / \mathrm{E}>2), \%\end{array}$ & 2.00 & 2.70 & 0.80 \\
\hline $\begin{array}{c}\text { Normal } \\
(\mathrm{Z} \text { T/E -1 a 1), } \%\end{array}$ & 38.40 & 44.00 & 35.80 \\
\hline $\begin{array}{c}\text { Stunting risk } \\
(\mathrm{Z} \mathrm{T} / \mathrm{E}-2 \text { a -1), \% }\end{array}$ & 30.80 & 34.20 & 29.50 \\
\hline $\begin{array}{c}\text { Stunting } \\
(\mathrm{Z} \mathrm{T} / \mathrm{E}<-2) \%\end{array}$ & 24.30 & 16.60 & 29.10 \\
\hline $\begin{array}{c}\text { Severe stunting } \\
(\mathrm{Z} \mathrm{T} / \mathrm{E}<-3), \%\end{array}$ & 4.50 & 2.50 & 4.80 \\
\hline
\end{tabular}

The percentages of high stature were $2.0 \%, 2.7 \%$ and $0.8 \%$ when used NCHS, CDC and $\mathrm{WHO}$ respectively, showing that children with high stature (2\%) according NCHS changed to healthy condition $(1.2 \%)$ when were evaluated with the new WHO growth pattern.

The prevalence of wasting (including severe wasting) was greater with the $\mathrm{CDC}$ reference (4.1\%), followed by WHO $(1.4 \%)$ and NCHS $(0.9 \%)$. The highest prevalence of overweight was observed with WHO reference, followed by the CDC and NCHS (Table 3).

Table 3. Nutritional classification based on Z-score weight/height - Period 1992 to $2007(\mathrm{n}=2640)$.

\begin{tabular}{|c|c|c|c|}
\hline & NCHS & CDC & OMS \\
\hline $\begin{array}{c}\text { Weight for height excess } \\
\text { (Z W/H>2), \% }\end{array}$ & 10.50 & 12.10 & 16.40 \\
\hline $\begin{array}{c}\text { Normal } \\
\text { (Z W/H -1 to 1) \% }\end{array}$ & 76.20 & 69.20 & 73.60 \\
\hline $\begin{array}{c}\text { Wasting risk } \\
(\mathrm{Z} \text { W/H -2 to -1) } \%\end{array}$ & 12.50 & 14.70 & 8.70 \\
\hline $\begin{array}{c}\text { Wasting } \\
(\mathrm{Z} \text { W/H -3 to -2), \% }\end{array}$ & 0.90 & 3.30 & 1.40 \\
\hline $\begin{array}{c}\text { Severe wasting } \\
\text { (Z P/E <-3), \% }\end{array}$ & 0.00 & 0.80 & 0.00 \\
\hline
\end{tabular}

The obesity-overweight prevalence (IBM Z-scores) was higher with CDC (15.5\%) than WHO (8.9\%). By contrast, the highest percentages of thinness risk and thinness were registered with WHO, with higher percentage of children classified as regular (Table 4). 
In Tables 5 to 9 and Figures 1 to 4 trends of underweight, stunting, wasting, and overweight and obesity prevalence's based on weight for age and BMI are shown.

Table 4. Body condition (Z IMC) - period 1992 to $2007(n=2640)$

\begin{tabular}{|c|c|c|}
\hline Body condition & CDC & OMS \\
\hline Obesity (Z IMC $>3$ ), $\%$ & 4.10 & 0.90 \\
\hline Overweight(Z IMCP/E 2 to 3), \% & 11.40 & 8.00 \\
\hline Normal (Z IMC -1 to 1), \% & 67.50 & 72.70 \\
\hline Thinness risk(Z IMC -2 to -1), \% & 15.80 & 16.20 \\
\hline Thinness (Z P/E <-2), \% & 1.20 & 2.20 \\
\hline
\end{tabular}

Table 5. Historical trend of underweight prevalence with each reference period 1992 to $2007(\%)$.

\begin{tabular}{|c|c|c|c|c|}
\hline Z(W/A) & 1992 & $1993-1997$ & $1998-2002$ & $2003-2007$ \\
\hline NCHS & 10.50 & 7.60 & 13.40 & 5.70 \\
\hline CDC & 13.00 & 8.90 & 15.60 & 4.30 \\
\hline WHO & 8.60 & 6.20 & 15.60 & 10.10 \\
\hline
\end{tabular}

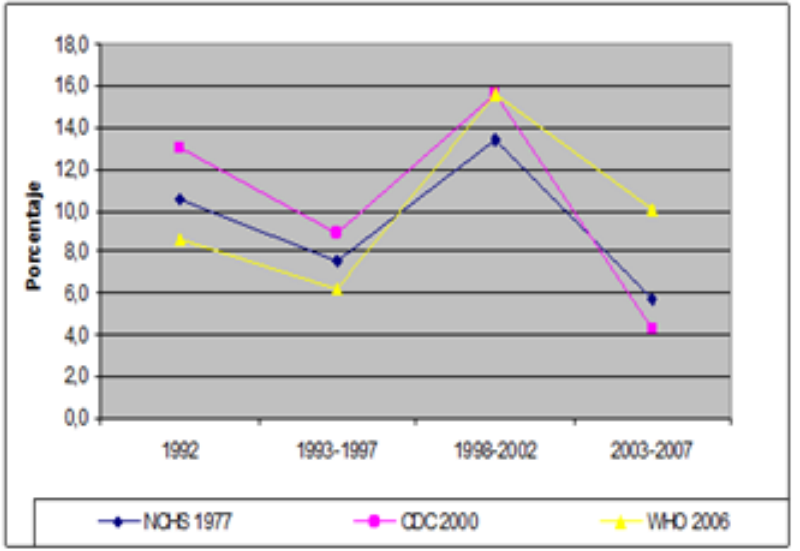

Figure 1. Historical trend of underweight prevalence with each reference - periods 1992 to 2007 (\%).

Table 6. Historical trend of stunting prevalence with each reference period 1992 to 2007 (\%).

\begin{tabular}{|c|c|c|c|c|}
\hline $\mathrm{Z}(\mathrm{H} / \mathrm{A})$ & 1992 & $1993-1997$ & $1998-2002$ & $2003-2007$ \\
\hline NCHS & 34.80 & 40.20 & 30.40 & 22.20 \\
\hline CDC & 23.30 & 28.30 & 21.00 & 13.70 \\
\hline WHO & 44.60 & 28.30 & 36.50 & 27.30 \\
\hline
\end{tabular}

Table 7. Historical trend of wasting prevalence with each reference period 1992 to 2007 (\%).

\begin{tabular}{|c|c|c|c|c|}
\hline $\mathrm{Z}(\mathrm{W} / \mathrm{H})$ & 1992 & $1993-1997$ & $1998-2002$ & $2003-2007$ \\
\hline NCHS & 1.90 & 0.50 & 0.00 & 0.90 \\
\hline CDC & 4.50 & 2.40 & 1.80 & 5.10 \\
\hline WHO & 1.90 & 0.50 & 0.40 & 1.80 \\
\hline
\end{tabular}

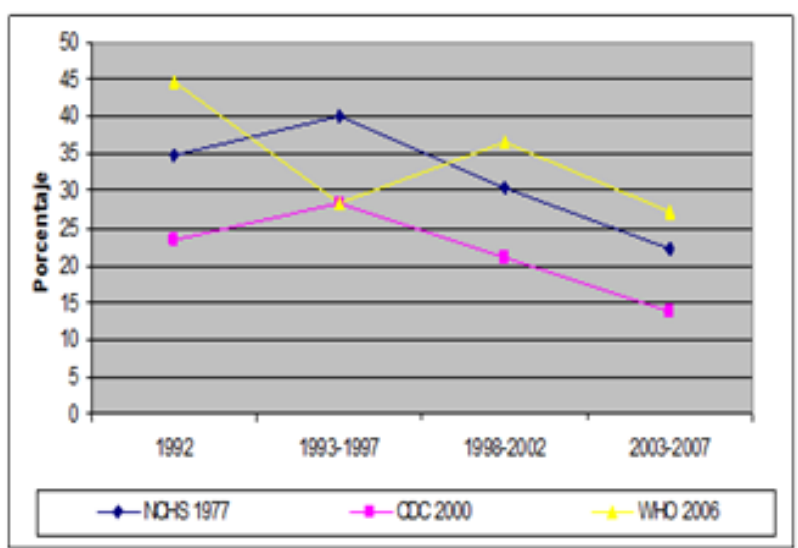

Figure 2. Historical trend of stunting with each reference - periods 1992 to $2007(\%)$.

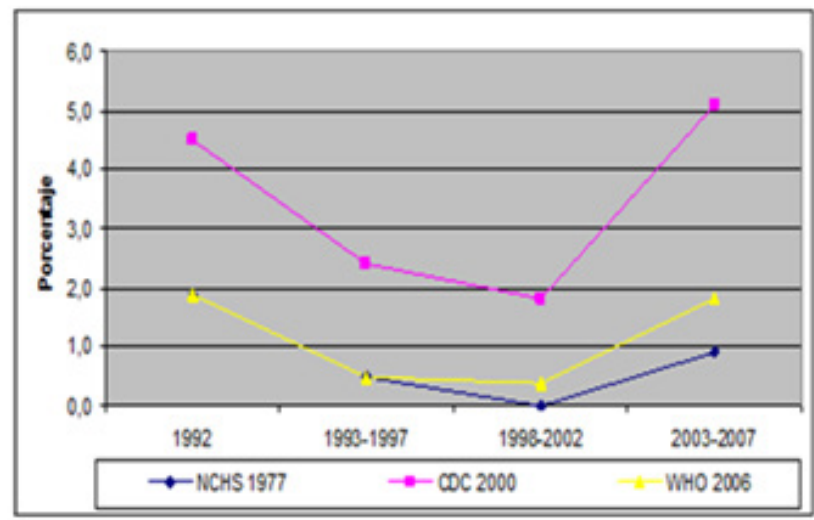

Figure 3. Historical trend of wasting with each reference - periods 1992 to $2007(\%)$.

Table 8. Historical trend of overweight-obesity prevalence with each reference - period 1992 to 2007 (\%).

\begin{tabular}{|c|c|c|c|c|}
\hline $\mathrm{Z}(\mathrm{W} / \mathrm{H})$ & 1992 & $1993-1997$ & $1998-2002$ & $2003-2007$ \\
\hline NCHS & 0.80 & 1.60 & 2.80 & 2.60 \\
\hline CDC & 0.80 & 1.10 & 3.40 & 2.90 \\
\hline WHO & 0.40 & 0.80 & 2.80 & 2.50 \\
\hline
\end{tabular}

The prevalence of overweight and obesity from 1992 to 2007 has increased an issue that has to be treated very carefully for preventing problems like malnutrition at the adulthood.

With WHO pattern, the overweight-obesity prevalence in children (36-60 months) in Huancayoprovince increased 6.25 times in 16 years $(0.4 \%$ to $2.5 \%)$, if the trend continues the problem will become increasingly difficult to solve. The overweight-obesity prevalence assessed from the years 1992 to 2007 is going to rise. 


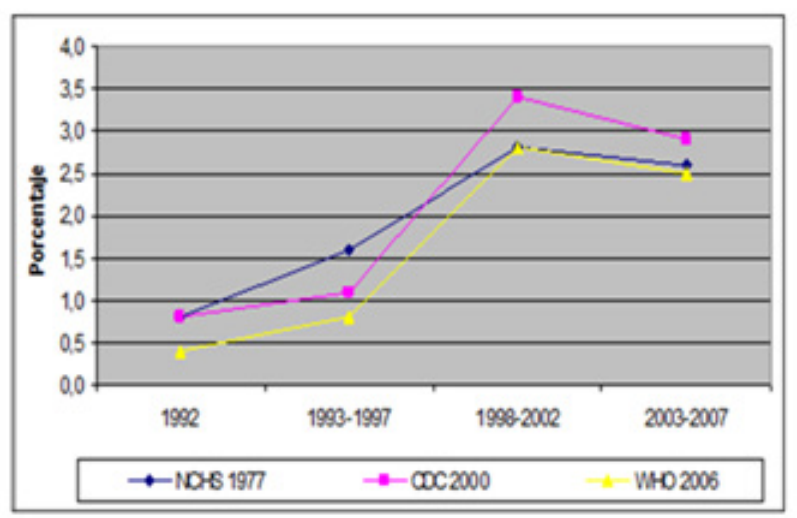

Figure 4. Historical trend of overweight-obesity (W/A) prevalence with each reference - period 1992 to 2007 (\%).

Table 9. Historical trend of overweight-obesity prevalence classified with the standard NCHS and CDC- periods 1992 to 2007 (\%).

\begin{tabular}{|c|c|c|c|c|}
\hline Z (IMC) & 1992 & $1993-1997$ & $1998-2002$ & $2003-2007$ \\
\hline CDC & 13,50 & 12,10 & 16,60 & 17,10 \\
\hline WHO & 8,10 & 8,40 & 5,30 & 10,70 \\
\hline
\end{tabular}

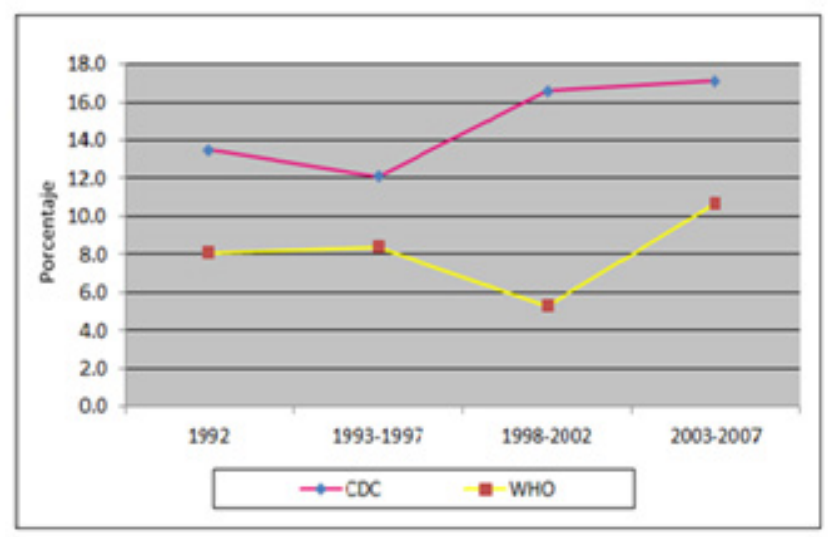

Figure 5. Historical trend of overweight-obesity prevalence (BMI) with CDC and WHO references - period 1992 to 2007 (\%)

\section{Discussion}

The highest prevalence of overweight (including obesity) based on weight for age was determined with CDC reference. This result confirms the findings of several authors $[2,19,21,25,26]$, who consider the concept was resumed for BMI-CDC reference to identify weight problems due to the overweight epidemic.

With respect to the assessment of nutritional status based on height for age, the new WHO pattern determined greater stunting prevalence, increasing by $5.1 \%$ compared to the NCHS reference and $14.8 \%$ regarding with CDC reference. With the new WHO pattern, relative to NCHS, stunting percentage increased by $17.71 \%$ ( $28.8 \%$ vs. $33.9 \%)$. This result validates and allows considering the proposed new anthropometric assessment as the most suitable for use in our conditions, as suggested by WHO [29].
In nutritional assessment based on weight for height, WHO pattern determined $5.9 \%$ more of excess weight for height than NCHS standard (16.4\% vs. $10.5 \%)$, while CDC standard determined $1.6 \%$ more children with excess weight for height than NCHS $(12.1 \%$ vs. $10.5 \%)$. Respect to wasting, WHO pattern determined $0.5 \%$ more than NCHS. The new WHO pattern allowed us to determine more realistically and accurately the excess weight problem than CDC and NCHS.

With regard to obesity and overweight condition assessed by the BMI, CDC reference detection was $6.6 \%$ more than WHO pattern, equivalent to 1.74 times more (15.5:8.9). This result recommends using $\mathrm{CDC}$ reference as intervention strategy to counteract the weight excess problems. $[2,8,14]$.

The historical trend in the prevalence of underweight (W/A) evaluated during 16 years was different with the three systems. For the final evaluation period (2003-2007) the WHO pattern detected $4.4 \%$ more of underweight prevalence than NCHS standard (10.1\% vs. $5.7 \%)$ (Table $5)$.

The historical trend in the prevalence of underweight (W/A) evaluated during 16 years was different with the three systems. In the last evaluation period (2003-2007) the new pattern assessed more accurately this nutritional problem. This result confirms WHO recommendations: worldwide usage.

The prevalence of underweight evaluated from 1992 to 2007, regardless of the standard used, was higher between 1998 and 2002, then a substantial decline in 2003-2007 was observed. The 1991 economic shock caused by government policies affected the population food security especially the poor and extreme poverty in the rural highlands.

In evaluating the historical trend of prevalence of chronic malnutrition with different patterns in 16 years, it appears that the $\mathrm{CDC}$ reference underestimates this problem, percentage rose when using the NCHS and WHO references. When comparing the two main references, NCHS and WHO, in the period 2003-2007, the prevalence of malnutrition in children 36-60 months of age in the province of Huancayo, rose by $5.1 \%$ (22.0 to $27.3 \%$ ). These results are in line with reports of National Health Institute [3], who show that the stunting average prevalence in Junin Region which was $25.4 \%$ with the NCHS, step by $31 \%$ when was used the new WHO pattern.

The percentages of overweight and obesity based on BMI determined by CDC reference are much higher than those calculated with WHO standard. The percentage was 59.8\% higher than the WHO pattern $(17.10 \%$ vs. $10.7 \%)$ showing large differences between two patterns for assess overweight and obesity. These results validate the CDC model for a more accurate detection of overweight problems.

The average percentage of stunting by the year 2007 was $22.6 \%$ [3], problem that is complicated by the simultaneous presence of overweight and obesity $[7,14$,$] in the same$ community, even in the same family $[15,17,18]$, where rural 
diet is characterized by potato, rice, wheat, barley and noodles, generating health risks when these children become adults [8].

The high stunting percentage in children under five in Huancayo province determined in this study has a negative impact on future development of this population, because the poverty cycle and malnutrition remains as a public health problem which slowly decreases as overweight and obesity increase.

\section{Conclusions}

The new international pattern for nutritional assessment of children under 5 recently proposed by the WHO allows measure malnutrition prevalence in a more realistic and accurate way, either by deficiency or excess, in comparison with NCHS or CDC references. Therefore, we believe that the new growth of the WHO-2006 is a reliable model for widespread use in the central highlands of Peru.

\section{Recommendations}

The government and non-governmental organizations and research centers of Junin Region should use the new standard for monitoring the welfare of children in order to devise strategies for promotion, prevention and intervention and contribute in the future to reduce of chronic problems of adulthood.

The institutions committed to the health and nutrition of Junin Region should systematize their databases with the new pattern of anthropometric assessment.

\section{REFERENCES}

[1] INEI. 2012. Evolución de la Pobreza en el Perú al 2011. Disponible en: http://www.inei.gob.pe/DocumentosPublicos/ Pobreza_ExposicionJefe.pdf

[2] J. Castro, E. Ríos, N. Solomons, G. López de Romaña. Diagnóstico del estado nutricional mediante los sistemas Z-score e Índice de Masa Corporal (CDC-2000) en niños de la ciudad de Chiclayo. Resúmenes IV Congreso de la Red Científica Peruana. Lima. Perú. 2004.

[3] INS. 2010. Desnutrición crónica infantil y sus determinantes de riesgo. Ministerio de Salud. Instituto Nacional de Salud. Lima, Perú. Disponible en: http://www.ins.gob.pe/ repositorioaps $/ 0 / 5 / \mathrm{jer} / \mathrm{prec}$ invt cenan/Presentacion\%20Des nutrici $\% \mathrm{C} 3 \% \mathrm{~B} 3 \mathrm{n} \% 20$ Determinantes.pdf.

[4] ENDES. Informe Principal de la Encuesta Demográfica y de Salud Familiar. InstitutoNacional de Estadística e Informática-INEI. Lima. Perú. 2000.

[5] J. Castro, D. Chirinos, E. Ríos. Estudio Basal de la Seguridad Alimentaria Nutricional del distrito de Janjaillo, Jauja. Informe Final. Instituto de Seguridad Alimentaria Nutricional.
ISAN-Universidad Nacional Agraria La Molina. Lima. Perú. 2009.

[6] J. Gerald and DR. Friedman. 2001. Reduction of Chronic Malnutrition in Peru: Proposal for a National Strategy. School of Nutrition Science and Policy at Tufts University. USAID.

[7] APOYO. Política Nacional para la Reducción de la Desnutrición Crónica en el Perú. InstitutoApoyo. Lima. Perú. 2001.

[8] M. de Onis, M. and M. Blössner. Prevalence and trends of overweight among pre-school children in developing countries. Am J ClinNutr 2000;72:1032-9.

[9] D. Chirinos, J. Castro, E. Solís. 1998. Evaluación del Estado Nutricional de Niños en edad pre-escolar del Distrito de Uñas. Centro de Investigación. Informa Final. Universidad Nacional del Centro del Perú. Huancayo, Perú.

[10] INEI-EMPRE. Encuesta Nacional de Consumo de Alimentos. INEI. Lima. Perú, 1975.

[11] ENSA. Encuesta Nacional de Salud y Alimentación. INEI. Lima. Perú, 1984.

[12] ENDES-91. Encuesta Nacional Demográfica y de Salud. INEI. Lima. Perú, 1992.

[13] INS. Monitoreo Nacional de Indicadores Nutricionales (MONIN-CENAN). Prevalencia de desnutrición crónica en niños menores de 05 años. Documento de Trabajo. InstitutoNacional de Salud. Lima, Perú. 2004.

[14] J. Pajuelo, M. Villanueva, J. Chávez. La Desnutrición Crónica, el Sobrepeso y la Obesidad en niños de áreas rurales del Perú. Anales de la Facultad de Medicina 2000; 61: 201-6.

[15] INEI. Estado de la Población Peruana 2002. Instituto Nacional de Estadística. Lima. Perú. 2002.

[16] ENDES. Encuesta Demográfica y de Salud Familiar. INEI. Lima. Perú. 2005.

[17] B.M. Popkin. Nutrition Transition in low-income countries: An emerging crisis. Nutrition Reviews 1994; 53:275-289.

[18] T. Gill, VJ. Antipatis, WPT. James. The global epidemic of obesity. Asia Pac J ClinNutr 1999; 8;75-81.

[19] JS. Garrow, J. Webster. Quetle's Index (W/H2) as a measure of fatness. Int J Obesity 1985; 9:147-153.

[20] NCHS. National Center for Health Statistics Version Centers for Disease Control and Prevention 2000 Growth Charts for the United. States: Improvementstothe 1977. 2000.

[21] OMS. Patrones de crecimiento infantil de la OMS: Longitud/estatura para la edad, peso para la edad, peso para la longitud, peso para la estatura e índice de masa corporal para la edad - Métodos y desarrollo. pdf. Organización Mundial de la Salud. Departamento de Nutrición para la Salud y Desarrollo. 2006.

[22] EpiInfo. A Nutricional Anthropometry Program. Epi Info 2000. Diponible en: ftp://ftp.cdc.gov/pub/epodphsi/Espa\% F1ol/GUIDED.HTM

[23] WHO. WHO Anthro 2009. Versión 3.0. Software and Macros. World Health Organization. Disponible en: http://www.who.int/childgrowth/software/en/. 
[24] WHO. Measuring change in nutritional status. Guidelines for assessing the nutritional impact of supplementary feeding programs for vulnerable groups, World Health Organization .Geneva. 1983.

[25] CDC. Growth Charts. National Health and Nutrition Examination Survey. Center for Disease Control and Prevention. USA. 2002.

[26] M. de Onis. AW. Onyango. The Centers for Disease and Prevention 2000 growth charts and the growth of breastfed infants. ActaPediatrica. 2003; 92:413-419.

[27] WHO. Physical Status: The use and interpretation of Anthropometry. World Health Organization. Technical
Report Series 854.Genova. 1995.

[28] M. de Onis, M. Blossner. World Health Organization Global Database on Child Growth and Malnutrition. WHO/NUT/97.4. 1997. Programme of Nutrition, WHO, Geneva, Switzerland. 1997.

[29] C. Garza, M. de Onís. Estudio Multi-centro sobre las Referencias del Crecimiento de la OMS. 2006.

[30] R. Gross, A. Kielmann, R. Korte, H. Schoenberger, W. Schultink W. Guidelines for Nutrition Baseline Surveys in Communities. SEAMEO-TROPMED and Deutsche GesellschaftfürTechnischeZusammenarbeit (GTZ). Bangkok: Southeast Asian J Trop Med Public Health, Suppl. 1997. 